Tobias Kraft

\title{
Reading in the Digital Age
}

\author{
Innovation, Failure and the Prospects of Digital Philology
}

\section{In-Between Cultures}

The history of the book has reached a tipping point with humankind's entry into the digital age. Consequences of this change have been visible for about 20 years, but its long-term impact on the future of reading is not entirely foreseeable. This is, justifiably, a controversial issue in current debates. The relevant positions generally circulate around arguments about cultural pessimism (the end of book culture is near), medium-specific diversification (print culture will find its new niche), and tech optimism (digital innovation will lead the way). In the midst of this ongoing debate, a puzzling discrepancy emerges. It is easy to diagnose an oversupply of digital technology cultures, Digitale Technikkulturen, but we lack a similarly developed set of cultural techniques for digital reading, Kulturtechniken des Digitalen Lesens.

This essay attempts to provide some reflections and observations on this crucial issue, and first focuses on the realities of digital reading in our time. They pose a challenging question: will there be a change in the way we consume, process, and share the texts we read?

\section{The Subtle Routines of Disruption}

Let us start with everything that has changed. Digital transformation has been capturing our attention for almost three decades and is constantly reminding us of its inert but subtle need for action. We have gotten used to its consequences. If the entire music industry transitions from one paradigm to another due to the introduction of an end consumer product that facilitates our use of mp3 files, we take note of that while buying iPod after iPod. We immediately update our habits. If the same industry changes again because of a Swedish start-up that teaches us in little more than a decade (or much less, depending on the country you live in) that we do not want to posses, rather access the music we

Tobias Kraft, Berlin-Brandenburgische Akademie der Wissenschaften

Ә Open Access. ( 2021 Tobias Kraft, published by De Gruyter. (c) BY-NC-ND This work is licensed under a Creative Commons Attribution-NonCommercial-NoDerivatives 4.0 International License.

https://doi.org/10.1515/9783110713015-022 
love, then we do it, pay our subscription, and move on with our lives. The same can be said, of course, for the ways in which we consume TV series and movies, manage our private economies with an app, learn to trust strangers while moving through foreign towns, sleep in apartments that are owned by strangers, and so on. These sudden, but fundamental agents of change are called disruptive economies. They have indeed disrupted, and very effectively at that, not only our 19th and 20th century lifestyles, but the cultural techniques that we put into practice while doing the things we like.

The point of this text is to show that this is not happening (yet) in the case of reading. By reading I mean deep reading; the kind of intellectual exercise we undertake when we truly (try to) focus on a continuous stream of text with coherent composition. Instead of disruptive change or the evolution of one of our most distinct cultural techniques, something, or many concurrent things, are happening differently. The messiness of this situation has not helped us to see the road ahead clearly, nor even to know what we are talking about, should study, teach, or investigate when we think about reading in today's world. To highlight my point, I will discuss three topics in particular:

1. the failure of innovation

2. the pioneering role of scholarly digital editions

3. perspectives for future (digital) philology.

These three topics sound more ambitious than my capacity to making sense of them might be, so I need to start with a disclaimer. This is merely a first draft of thoughts and observations mixed with some worries and hopes, all of which have been wandering through my head for a couple of years. Additionally, to state the obvious, a midsize paper like this can only provide first impressions of what I would like to extend into broader research in the upcoming years. It is also, of course, a very particular view on reading in the digital age, and many other perspectives, such as cognitive psychology, interface design theory, cultural anthropology, history of reading, and hermeneutics in its many shapes and forms, could be applied. This is also not about the field of research coined by Franco Moretti as "distant reading” (Moretti 2013). I will not talk about the tools, methods, and intellectual outcomes of digital textual analysis. I will not so much focus on the things we can do with digital texts, but on the act of reading itself, as well as on the changing position of the reader as a main agent in this process.

I am, nevertheless, convinced that the future of reading in the digital age is not yet defined with any degree of clarity. It has been vastly understudied or ignored by general academia, in part because the craft of philology has not risen to the challenge. 


\section{The Failure of Innovation}

A natural choice for a discussion on contemporary reading is to start with the evolution of digital publishing. Considering everything else that has changed in the last 20 years, the current state of affairs is surprising. It can be summed up in a few words: there is, for sure, a lot of diversity, but change has not occurred. We still read as we always did, or we stopped deep reading altogether ${ }^{1}$ because of everything else that has been happening, consuming our attention, and satisfying our need for digital procrastination. Both scenarios do not provide insights into the lagging culture in digital reading.

When we actively change the way we make sense of the world, we do it because of a change in experience. If we look at books, or more specifically at reading in the digital age, that experience has not yet happened for most of us.

\section{The Dead End of Commerce}

A personal experience first: 20 years ago, in the spring of the year 2000, I was working as an intern for Deutsche Welle, the German public world broadcasting organization. After a couple of weeks, I was given the opportunity to interview stakeholders at a conference on media transformation in Heidelberg. Among other people, I talked to the representative of a large German publishing house that was announcing a breakthrough strategy they were pursuing on e-books. Of course, everybody was talking about e-books in the year 2000: their unique selling proposition, their easy-to-access approach, their advantages over ink and paper. The e-book was the future; the agent of change for selling, consuming, and reading books. I had, as many did, my doubts.

Today, 20 years later, the e-book might have found its $10-20 \%$ niche in certain sectors of literature consumption, mostly attracting already avid readers (Barnett 2014: 144), facilitating an easier pathway towards text distribution bypassing the traditional bookseller retail industry. Some people now read their leisure or summer vacation literature on a Kindle or tablet and praise the mobility

\footnotetext{
1 A good overview on this generalized observation is presented in Hayles (2010: 62-68), who cites and discusses several recent studies on (digital) reading and technologies of distraction. The study mostly discusses and summarizes the case of US-American and Canadian readership and cannot therefore completly be transfered to a more global remark on the matter. In light of a decline in close reading capacities, Hayles makes a strong case for a change in disciplinary leadership due to the rise of digital reading. This is an important point to which I will come back later in this essay.
} 
of their digital bookshelf. All of this is true, but does anyone still think the ebook has changed the book industry in a way that most people, both promoters and their adversaries, predicted? Even the most engaged readers of digital-born literature, most of between 13 and 24 years old, reported in a recent worldwide survey by the digital literature site Wattpad that they still widely prefer print paperback to e-books (Pianzola/Rebora/Lauer 2020: 13).

The story of the e-book is full of technological disasters. Since 1989 when the company Franklin Computer created the first stand-alone device for the display of electronic texts (in the form of the Bible ${ }^{2}$ ), the technological hardand software development of the e-book has seen many shapes and forms. Even Amazon's Kindle has not managed to break through the barrier and provoke the type of disruptiveness we ought to expect from a company that revolutionized the way online shopping functioned, albeit at a high cost for workers, bookstores, and small publishing houses. The notorious reliance of small publishers on the globally active distributor Amazon becomes particularly apparent in times of crisis, as the current Covid-19 pandemic shows. While the owner-managed publishing houses were previously at an advantage because they could present their books on an equal footing with the big publishing houses, Amazon's decision in mid-March 2020 to largely suspend print book sales until April has led to serious losses in turnover, which endangers the existence of the small publishing houses (Börsenverein des Deutschen Buchhandels 2020). E-book sales are likely to increase as a consequence of this decision, but concentrated in-depth reading will lose ground if the books it requires are suddenly no longer available and if no electronic alternatives have been developed to compensate for this loss. The US company's decision, which was based solely on profit considerations, provides an indication of the simultaneously diagnosed lack of innovation. Where there is no money to be made, there is no progress. The economisation of such a fundamental cultural technique as reading then inevitably has fatal consequences for the culture of digital reading.

To make it short, the e-book has not provided an experience that produced change. It has done little for the culture of books and nothing for reading. It is a technological and cultural dead end. Given the lack of commercial innovation, some branches of international academia have explored other means of enhancing the book and its reading experience in the digital age.

2 See https://en.wikipedia.org/wiki/E-book for a comprehensive list. 


\section{A Short Typology of Recent Digital Publishing in Academia}

\section{Debates in the Digital Humanities}

One example of digital innovation can be seen in the case of Debates in the Digital Humanities, a publication that is both digital and printed. It was created in 2012 as an interactive, openly accessible platform by the University of Minnesota Press, the Graduate Center at the City University of New York, and the digital development agency Cast Iron Coding. The project has grown since then into a full-scale digital publishing platform under the brand Manifold, and keeps growing as a non-profit entity with funding from the Andrew W. Mellon Foundation ${ }^{3}$. According to the editors Matthew K. Gold and Lauren F. Klein, the Debates platform

will address the core challenge of publishing today: attending to the increasing pace of scholarly conversation at a time when the gap between print and digital continues to grow, while also acknowledging the continuing value of print publication. In both form and process, Debates in the Digital Humanities will model a hybrid scholarly publishing process that takes account of networked forms of scholarly communication ${ }^{4}$.

The Debates project was well designed and combined content (the Digital Humanities) and form (a common space of textual debate and commentary) in a simple, yet smart way. Since its first publication in 2012, the series has seen two follow-up volumes, one in 2016, and another in 2019, with many more to come ${ }^{5}$. The three digital Debates volumes were recently updated in January 2020, and the site has seen an overall upgrade in usability and typographic design, including tools to fully personalize your reading experience via adding your own public or private annotations. The editors Gold and Klein continue to publish open access, full text materials through the Manifold Project site, while their publishing house, University of Minnesota Press, provides commercial book sales of the same texts in paperback and pricey clothbound editions ${ }^{6}$. The continuity and quality of the project is remarkable, and it makes an important contribution to the field. Unfortunately, it fails at its larger goal, which is presumably to create, or at least pilot, new ways of reading and debating critical essays online. The implicit proposition to turn a personal reading experience into an act of scholarly debate never gained real traction.

3 https://manifoldapp.org/learn.

$4 \mathrm{http}: / /$ dhdebates.gc.cuny.edu/news.

5 https://dhdebates.gc.cuny.edu/projects/all.

6 https://www.upress.umn.edu/book-division/books/debates-in-the-digital-humanities-2016. 

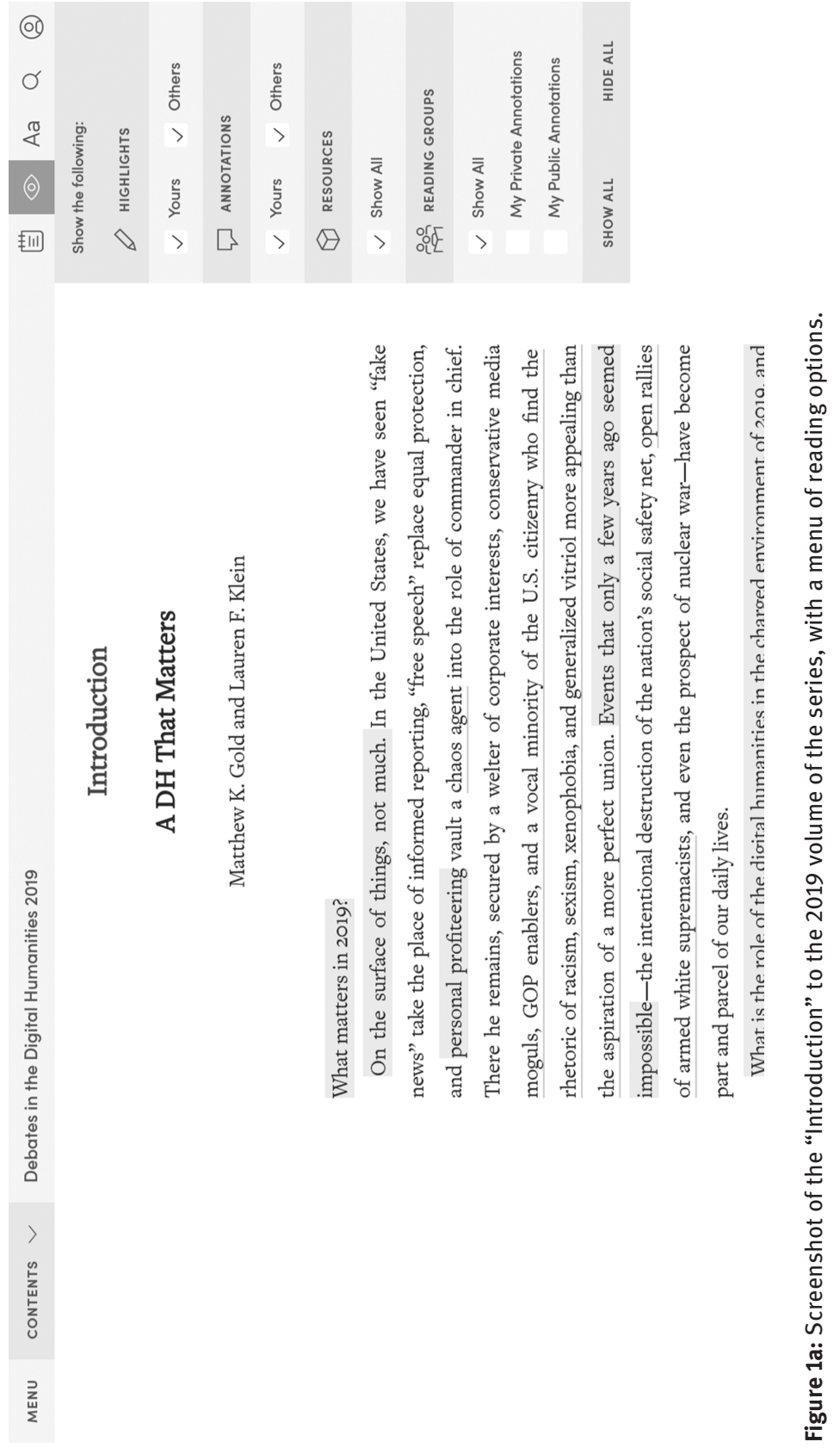


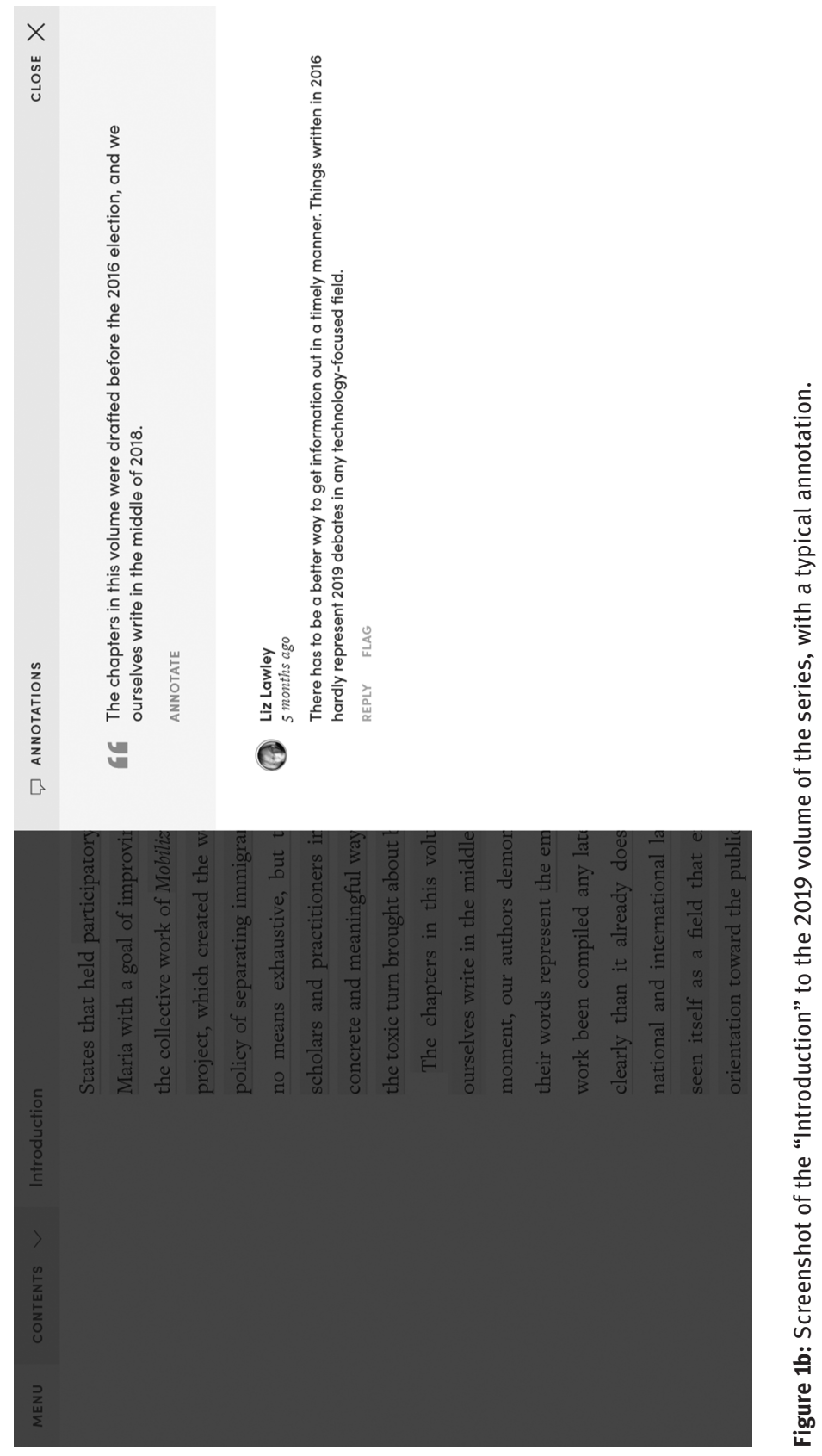


These two screenshots (Figure 1a, Figure 1b) highlight the problem. Somebody did leave a commentary, in this case in the form of a criticism about the very book-like timeframe in which the production of this highly digitized text came to being. The commentary is directed at the printed, slow moving nature of the text, circulating in an era when world events seem to overwrite and outdate the very work we do in a matter of months. The commentary is obviously directed towards the volume's editors, but there is no feedback, no conversation, no debate, and as far as I could observe, this was the case in most situations. A social networking approach applied to online reading simply never takes off. What we witness instead are singular traces of insular readings, lost in digital translation.

It is almost as if the Debates website - not due to its academic content, but because of its socio-technological format - manifests itself as one of those historic attempts to turn web culture into a new social practice. These attempts have already become historic, because, unfortunately, we now live in a world different to 2012. The idea of the web (and digital publications, for that matter) as a space for social debate and communication relies on false premises. The web, as these premises assume, is not a social place of communal (or even common) sense, and technology applied in the form of simple interface design does not necessarily lead to a platform becoming a place of conversation. What we know, and keep referring to, as social media is, in fact, a combination of algorithms and manipulative psychology designed to direct our attention and consumer habits towards singular platforms, or perhaps just to Facebook ${ }^{7}$, the de facto monopolist in the social media realm of digital capitalism. It is not a place for social communities, but, as Sascha Lobo pointed out, a "digital social infrastructure, which changes the public sphere, politics and political communities of entire countries" (Lobo 2018; translation T.K.). The Cambridge Analytica scandal, which has gained world-wide attention since the 2016 article by investigative journalists Hannes Grassegger and Mikael Krogerus, shows the dramatic backflip of this infrastructure. The political and legal consequences of the scandal have been widely discussed in public ${ }^{8}$ and thoroughly covered by the Netflix documentation The Great Hack (Amer/Barnett/Kos 2019). Its implementations go way beyond the manipulation of national elections, which was bad enough. Facebook as the social media platform epitomizes the new reality of a global system of collectively organized emotions (Lobo 2018). In comparison to this new reality, which gained global coverage in the last five to

7 By referring to Facebook, I mean primarily the company Facebook Inc. and its products: Facebook, Instagram, and WhatsApp, although the company has already a much broader business model.

8 See, for instance, the comprehensive collection of press coverage and essays at https:// medienwoche.ch/tag/cambridge-analytica/. 
seven years, the idea of digital books as a place of socio-academic debate culture seems, unfortunately, naively out-of-date. The reason is, again, simple. All of us were wrong about the internet.

There are, however, other examples of similar projects that need to be highlighted briefly. They all bring us back to the initial question about the status and possible outcomes of digital publishing and digital reading.

\title{
The Living Books about History
}

This Living Books project was initiated in 2016 by the Swiss history platform infoclio. It portrays itself as,

\begin{abstract}
a new form of scholarly publication and seeks to test the potentials of digital media in innovative ways. It revives the anthology form and connects scholarly articles and sources virtually through hyperlinks. Readers can participate in Living Books about History by suggesting further contributions, which will be added to the table of contents after approval by the editors ${ }^{9}$.
\end{abstract}

Living Books presents an open access anthology of important essays, primary sources, and articles on diverse topics of cultural history (Figure 2). Their most innovative approach comes from the fact that they select and compose material already available elsewhere, first and foremost through public licensing. The project is, hence, more of an online aggregator, rather than a truly book- or reading-oriented attempt to change or do anything, really, besides providing an interface for texts that vaguely resembles the physical appearance of books. It needs to be highlighted that we are, in fact, talking about a very recent project, despite the fact that it conceptually embodies a vision of digital culture that dates back to the very early history of online media.

Once again there are intentions to provide something positive for scholarly reading, but there are still no advances or habit-changing processes in sight. This would not be such a problem if we were to actually read all these texts online, but the truth is we do not. The Stavanger Declaration, which sums up the collective effort of more than 100 scholars and scientists working for the European research initiative "Evolution of Reading in the Age of Digitisation", has recently been very clear about this:

Research shows that paper remains the preferred reading medium for longer single texts, especially when reading for deeper comprehension and retention, and that paper best

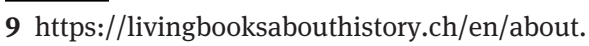




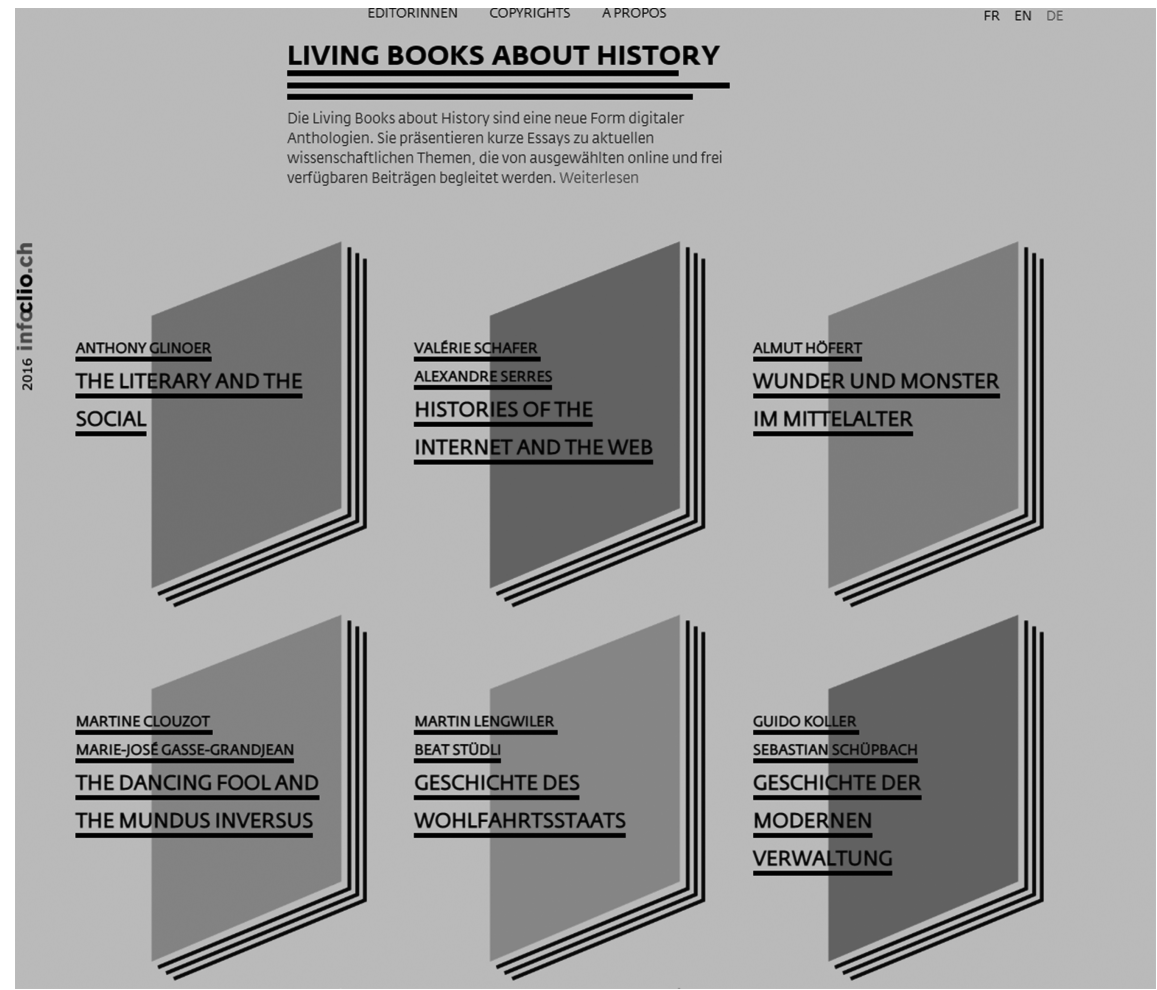

Figure 2: Screenshot of the landing page of Living Books about History.

supports long-form reading of informational texts. [. . .] [A]s screen use continues to grow, it will be one of the urgent challenges to discover ways in which to facilitate deep reading of long-form texts in a screen environment (E-READ 2019).

For now, deep reading is not happening. Not on these platforms, and not via simply redesigning text in resemblance to a book. Despite being decades into the digital transformation of (most of) our cultural artefacts and socio-cultural norms, we are still looking at quite uncharted territory.

\section{The GitBook Project: Introduction to Text Analysis}

This online publication by digital pedagogy scholar Brandon Walsh and historian Sarah Horowitz is meant as a workbook for classroom use, initially directed towards online history students at the University of Virginia. 
Each unit introduces students to a concept, a tool for or method of digital text analysis, and a series of exercises for practicing the new skills. In some cases, studies of particular projects are presented instead of tools in the third section of each unit (Walsh/Horowitz 2016).

The project was, "originally published with and hosted on GitBook", as the authors point out in the chapter "Adapting This Book" of their analysis (Walsh/ Horowitz: 2016). The $\mathrm{Git}^{10}$ approach was not only used as a means of publishing, but more specifically was created with editors and university teachers in mind. It was intended to be a tool they could use to copy the workbook and then change and reuse the adapted version of the original source code, all on the same platform. But GitBook, like so many other digital platforms (not just those for software development and frontend processing), proved to be "too unstable for us to develop reliable documentation ${ }^{11 "}$.

This is, in fact, a stunning conclusion. Let us be clear: four years ago, two experts developed an online textbook based on an infrastructure that has already become too unstable to adequately document their own work. The Introduction project had to be removed from GitBook and reorganized with different software and infrastructure (GitHub, GitHub Pages, Yekyll, as well as some code and admin tools) to stay alive and stable. And this is not the end of the anecdote. Today, the Lyon-based French company GitBook is apparently well-off and the platform seems to be back in business again. This indicates that the Introduction project could have very well stayed with its original infrastructure all along, but the economic recovery of GitBook was apparently not foreseeable. Digital start-ups and their emerging technologies come and go, research software engineers develop and fail, and some rise again. Is this a good environment for texts, as they are actually meant to be read?

10 The Git software was designed for code-based projects that imply a workflow of collaborative or generic development and adaptation. Git was originally developed by the Linux creator Linus Torvalds in 2005 and rapidly became the standard infrastructure for any kind of procedural, non-linear development of code-based text (mostly software). It serves as a repository and version-control system and is currently the most important source-code management tool available (https://en.wikipedia.org/w/index.php?title=Git\&oldid=938872488). It therefore combines well with the premise of creating a workbook that is made to be used, adapted and enhanced by others over time.

11 Coherently enough, this quote can only be cited from an archived version of the Introduction at https://bmw9t.gitbooks.io/introduction-to-text-analysis/content/conclusion/adapting.html. 


\section{Good Intentions Everywhere}

All three examples showcase different browser-based strategies for the publication of digital books. Obviously, there are many more, but let us sum up what we just saw:

1. The strong focus of the Debates project relies on what we might call a social media approach to scholarship. Being able to add comments and highlight passages in a textbook that is read by others who can also comment on the same text sounds like a promising way to achieve the goal that is implied by the title of the project, mainly creating the space for one or multiple debates on digital humanities. The result is visually convincing, but not intellectually stimulating. I still find myself reading a text onscreen with little motivation to include myself in the more or less anonymous space of co-commentators, which - this needs to be repeated - basically write into the void of the platform and never receive feedback, even from the books' editors.

2. The Living Books project basically takes advantage of the open access culture that has, in fact, been one of the blessings of the digital age. As a distribution device, the site provides a neat collection of resources, mimicking a printed book in its structures and layout. However, it ends up merely providing pathways to relevant resources on the web, encouraging others to participate in the gathering of online text resources. It does not even remotely enhance or advance anything related to text, the creation of books, or the habit of online reading.

3. The Introduction to Text Analysis is, in fact, a much more living digital object than the Swiss project ever can be, but this is only due to the permanent beta condition of the world of research software engineering ${ }^{12}$. If it were not for the personal capacities of editors Walsh and Horowitz to enhance their own product by alternative platforms and data models, we would now only be looking at an outdated version of a publishing project that had to move out of its house. While Walsh and Horowitz did explore venues of digital academic publishing, their efforts also show the harsh limitations of the digital technology culture we live in. The case certainly shows some sense for drama: a digital project that has set itself the goal of promoting a flexible publishing system in the field of literary analysis of digital texts, and thus aims at promoting new ways of digital reading and text comprehension, has to fight for its own digital survival because of the technology on which it relies.

12 This, by the way, also accounts for the Manifold software, on which the Debates project is based, cp. https://manifoldapp.org/docs/installing/ubuntu/index. 
The story of these platforms illustrates three major problems with current digital publications:

1. The social media approach has not worked out for us.

2. Online access to freely available text resources is good, but by itself does nothing to advance a digital reading experience.

3. To create a digital publication you need reliable resources and infrastructure. The web is currently not a good place for that.

The almost systemic problem of work-in-progress projects, which might at some point change their entire data model or stop support and development, has been the root cause for many good intentions to fall short of their own promises. This phenomenon of "perpetual beta" 13 caused a certain shift in the design of recent scholarly projects. The Introduction is a good showcase for that. It is crucial to underline the fact that the project moved to Jekyll software, which does support a database approach, but does not allow for comments or the moderation of any feedback loop. It does not create dynamic websites. It is, as they say, "just your content"14. Stable, reliable, self-sustaining.

This last observation might provide us with some perspective. Shifting the Introduction workbook to Jekyll is, in a way, a sign or symptom of a digital (scholarly) culture slowly moving towards a digital conservatism that stays away from perpetual beta development, dynamic infrastructures, bold design approaches, or social media endeavors. There seems to be a new desire to ensure the endurance of the digital text, not just by means of long-time archival repositories, but through the very core design of the textual object itself.

13 The term "permanent" or "perpetual beta" originates in the realm of agile software engineering and describes a process in which software is being launched to the public or a selection of beta users in an advanced but not final version. The further development and continuous improvement of the product is being done on-the-fly, in dynamic and participatory interaction with the users, which in return get accustomed to regular updates and feature enhancements at the cost of reliability. The provisional becomes the new normal. This model of continuous and iterative production and development cycles has expanded to multiple sectors of our modernday, high-potential (digital) work and creative life (Fredericks et al. 2019: 70-71). It is not hard to see how both the original and the expanded version of this "philosophy" have their roots in the ideology of deregulated liberal capitalism, in which the value of constant productivity, perpetual enhancement and growing net gain outweighs all other values and personal qualities.

14 https://jekyllrb.com/. 


\section{The Pioneer Role of Scholarly Digital Edition}

To ensure the endurance of text over time is precisely the mindset of scholarly editions and the academic practice of text philology. This is what preserving cultural heritage objects is about. Editing a canonical text or the works of a classical author is a task for both today's and future generations. It means working on a long-lasting object of shared textual heritage that provides a reliable resource for others. This kind of work needs professional care, long-term attention and stable public delivery.

This mission is not new. Scholarly editions have always posed special challenges for both books and reading. Throughout history they became, often unintentionally, a borderline experience, because not everything that those who preserve our written cultural heritage wanted to convey could be bound within the confines of a book. Oftentimes highly crafted, complicated scholarly editions whose legibility turned the experience of deep reading into a difficult, almost impossible task, were produced despite the most noble intentions of their creators (Sahle 2013a: 316-321). The roots of this problem lie in the content and the medium of philological practice. Scholarly editors work like text archaeologists, dissecting, documenting, and contextualizing different layers of text and meaning. This has, since the days of Karl Lachmann, been an exercise of methodological rigor. Due to that level of accuracy, philologists have always challenged the material, sensory, and even epistemological boundaries of the medium their scholarly work has been bound to.

The ambivalent practice of constant trial and error at the outer realms of book and print culture may explain why this discipline in particular has been able to sustain continuous momentum during the rise of global digital humanities, which has lasted for over 30 years. To this end, the Text Encoding Initiative (TEI) has been developing standards for the formal description and critical edition of texts in digital format. TEI has been working on this task since 1987 even before the World Wide Web (Cummings 2008: 453) - creating the largest consistency initiative in textual studies worldwide. The TEI Guidelines are created by and for textual scholars as an XML-based data model, and allow, not only to correctly capture character sequences in any kind of text, but also to integrate text structures, phenomena, and contextual information (such as metadata and critical apparatus) within the same data set (Schöch 2016: 332-337). This provides a high level of methodological coherence in the constitution of reliable text and text data for humanities projects. It allows all TEI-based projects to be perceived and used, not as individual publications, but as part of an increasingly global corpus of digital editions with comparable standards. The visualization of this information can lead to various output formats, such as a downloadable 
and re-usable XML source code, an HTML online edition, and a printed book or e-book edition.

All of these output options - TEI-XML, HTML, print and e-book formats (e.g. PDF, epub) - demand their own reading environment and produce their own reading expectations. This implies a complex "social contract" (Cohen 2012) with the potential readers of a scholarly edition. The term that Cohen invokes describes the interaction of supply and demand in the relationship between authors (or better: publicists) and readers. The reader of the printed book expects academic reputation, institutional embedding, prestigious publishing houses, scientific excellence, and high production quality. Scholarly digital publications of the last twenty years have tried to translate this social contract into the present with new formats and contents: "as topical portals, interactive maps, deep textual databases, new kinds of presses, primary source collections, and even software” (Cohen 2012). But this alone does not solve the problem of translating the symbolic capital of academic print culture into digital formats. Symbolic capital in the digital world arises "from the scarcity of attention" (Cohen 2012). It is therefore not only the quality of the texts once they have been produced that is important, but also the curation, maintenance and qualitative-functional expansion of this offer in iterative cycles. This fundamentally changes the publication process.

The data-driven approach of scholarly digital editing illustrates one of the many forms in which this new social contract under the conditions of digitally curated content. It formalizes many of the century-old practices of text philology in digital form, but it also pushes forward a hybrid model of publishing that goes way beyond the false premises of the (static) e-book and its unfulfilled promises to today's readers. The example of the Berlin-based edition humboldt might help illuminate this more clearly.

\section{The Process of Scholarly Digital Editions}

The hybrid scholarly edition humboldt is a product of the long-term research project "Traveling Humboldt - Science on the Move" (AvH-R ${ }^{15}$ ) whose offices are located at the Berlin-Brandenburg Academy of Sciences and Humanities (BBAW). The corpus comprises three major sections: a) the travel journals of the American (1799-1804) and b) of the Russian-Siberian Voyages (1829), a total of 12 bound manuscripts with more than 2,500 handwritten folios to be

15 The original German title of the project is "Alexander von Humboldt auf Reisen - Wissenschaft aus der Bewegung”. 
deciphered. As context to, and material beyond, the travel journals, AvH-R is also preparing c) the edition of selected correspondences and unpublished documents from Alexander von Humboldt's Nachlass ${ }^{16}$, mainly from the manuscript collections of the Berlin State Library (Staatsbibliothek zu Berlin, SBB) and the Jagiellonian Library in Kraków (Biblioteka Jagiellońska, BJ). The corpus contains a wide variety of material and textual forms, ranging from handwritten notes and working papers to literary and scientific essays, galley proofs, drawings and sketches, memos, excerpts of Humboldt's readings, and letters, covering the wide intellectual horizon of Humboldtian Science ${ }^{17}$. They are not only testimonies of the intellectual biography of one man, but provide important insights into a crucial moment in the transformation of modern European science and epistemic culture in the $19^{\text {th }}$ century.

\section{The Hybrid Publication Model}

The edition humboldt series consists of two parts. Since 2016, the edition humboldt digital has been publishing TEI-XML based texts and research data online as a work in progress edition. In 2020, the edition humboldt print sub-series will publish the first of its 16 volumes at the prestigious German Publishing House J.B. Metzler, which has been, since 2015, an imprint of Springer Nature ${ }^{18}$. The hybrid model follows the idea of a reader-text (print) on the one hand, and a critically expanded research-text and resource (online) on the other.

\section{edition humboldt print}

The print edition places a clear emphasis on legibility and coherence. The focus is on text continuity and critical commentary by the editors, not on a detailed

16 In this context, the German term "Nachlass" roughly translates as "personal papers and manuscripts" or "literary estate".

17 The term "Humboldtian Science" was introduced by Susan Faye Cannon (1978) and has since been in constant use in the international research communities working on Humboldt's legacy and the history of (Western) science in the $18^{\text {th }}$ and $19^{\text {th }}$ centuries. The term was later taken under scrutiny for further precision (Dettelbach 1996) and has recently been extended theoretically to articulate a conceptual matrix for defining the intellectual heritage linking the two brothers, Alexander and Wilhelm (Ette 2018).

18 See https://edition-humboldt.de/ and https://www.springer.com/series/16345 respectively. 
philological recording of all textual phenomena. The team's decisions while composing the print volumes were not governed by capturing the complete set of available manuscripts and correspondences. Instead, the aim is to publish selected documents and letters or, in the case of the travel journals, a comprehensible reconstruction of travel itineraries, in order to compile a curated collection of texts. This collection is supplemented by contributions from specialists in the relevant research fields of individual volumes, already providing a commentary on the freshly edited materials at hand.

Nevertheless, the print volumes should be seen as a curated derivative of the original source. All texts, both by Humboldt and from the scholarly community, are always published first in their (native) digital environment at https:// edition-humboldt.de.

\section{edition humboldt digital}

While the print edition is primarily aimed at a general public with an affinity for Humboldt, as well as a desire for linear reading coupled with concentrated text study, the online edition is a dynamic tool optimized for the needs of research, and satisfies the demand for textual philological criticism and data processing. The edition humboldt digital realizes this goal through a clear research data protocol (following the FAIR principles ${ }^{19}$ ), the digital curation of analog research results, and the integration of external resources and web services.

As is the case for most scholarly digital editions (Sahle 2013b: 148-149), the edition is flexible in its presentation of material. The online interface allows for a simultaneous display of the text-critical transcription and digital facsimile, while also providing a text display designed for online reading. The facsimiles and text transcriptions are linked to each other page by page, whereby the readability of the text is given priority over any attempt to imitate the exact layout of the manuscript. The conceptual principle of the edition thus follows a text-oriented, rather than document-oriented encoding.

Aside from its genuine mission to critically edit and publish formerly unpublished Humboldt originals, the digital edition also uses existing Humboldt research resources, and thereby sees itself as a data curating and aggregating platform (Figure 3). Among many other features, this applies to the integration of (previously printed) correspondence metadata and named entity recognition

19 See https://www.go-fair.org/fair-principles/. 


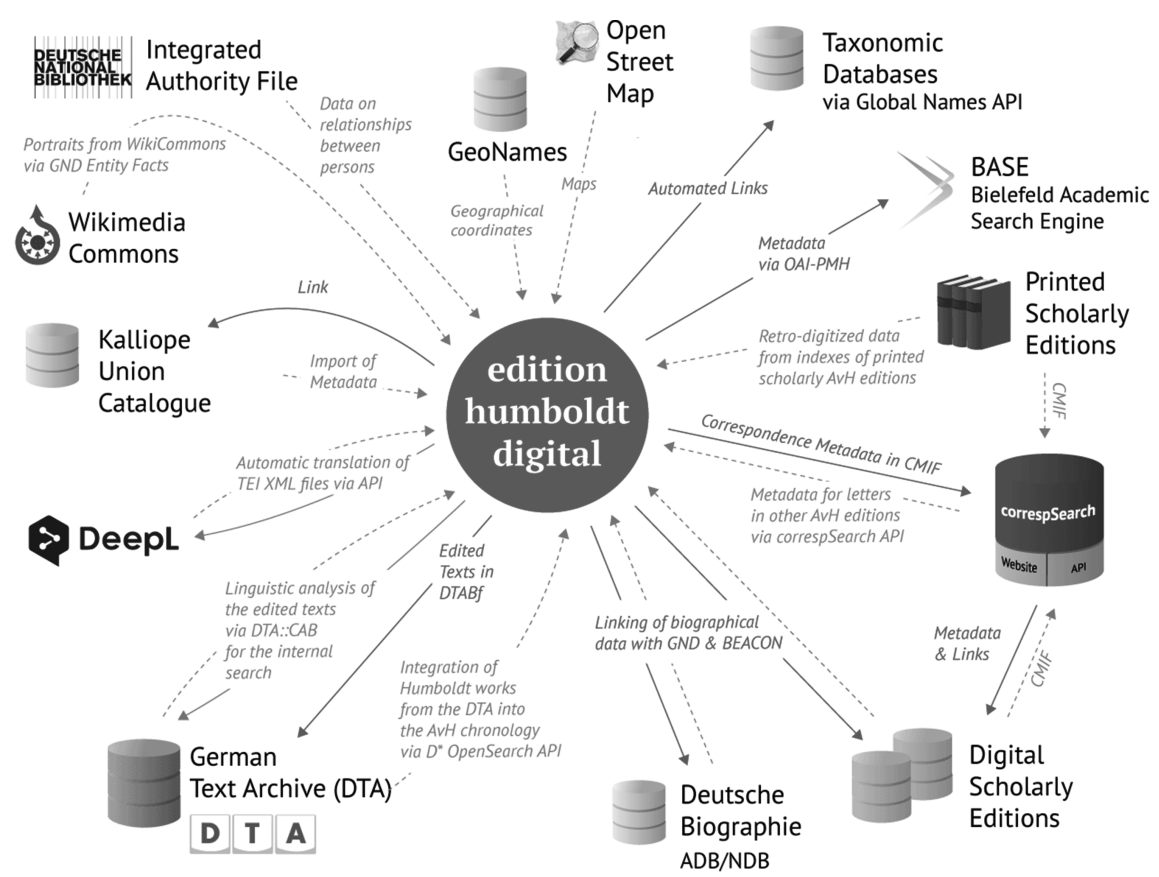

Figure 3: Visual model of the data driven concept behind edition humboldt digital. See also Dumont/Kraft (2017).

based research references. To this end, as well as in order to build up the place, person, and institution name index, the reference indexes 25 historic print editions of Alexander von Humboldt research published between 1973 and 2016, all integrated into the edition's database ${ }^{20}$.

The data curation of the Alexander von Humboldt Chronology, finally, incorporated a valuable information resource that has been highly relevant to the international Humboldt community since its first print publication in 1968 (Schwarz 2017). For more than fifty years, the Humboldt Chronology has provided the largest set of recorded and source proven life events in the field of Humboldt Studies, serving as a foundation for biographical and contextual research inquiries. In order to integrate these important data sets, the chronological entries of Humboldt's life were converted into more than 1,400 TEI-XML documents, and have been successively indexed within the named-entity database. Both the Print to HTML to XML conversion of the Humboldt Chronology, as well

20 For a more detailed discussion of the edition's digital approach see Kraft/Dumont (in press). 
as the creation of research data from printed indexes, saves the results of decades of research activity, thereby preserving their crucial relevance as resources for knowledge in digital times. It exemplifies the growing need for the digital curation of the type of research data that was previously only available in print.

The chronology's data is digitally supplemented with data from external resources through the API (application programming interface) and BEACON file of several web services like Wikimedia, GND Entity Facts, GeoNames, Open Street Map, and Global Names. A special "BBAW in-house feature" was developed via the integration of correspSearch (Dumont 2016), which aggregates correspondence metadata from many different scholarly projects and makes them available for research in several iterations of the digital edition. In addition, entries from the Calendar of the Prussian Court, in which Alexander von Humboldt is mentioned, can be displayed in the chronology, thereby combining the research data of two neighboring projects into one database via dynamic data assembling. The same can be said for all of Humboldt's publications published by the German Text Archive ${ }^{21}$, which includes a full-text search function integrated into the functionality of the chronology search mask (see Figure 4).

The cohesive approach of the hybrid edition humboldt combines the strengths of a reader-friendly book edition with those of a digital full-text and facsimile edition, all based on a carefully curated data infrastructure. Complementary to the advantages of the printed book for concentrated study of longer texts, the online edition offers a technological and methodological framework that provides a scholarly, reliable basis for research into Humboldt's work and life-long research activities.

\section{The Role of the Reader}

The hybrid setting of this scholarly edition (and many other comparable projects) profoundly changes the possible outcomes of the scholarly editorial process, both on the level of the publication itself and on the role it plays in providing both material and room for interpretation for the edition's reader. He or she sits, not on the mere receiving end of the publication chain, but is given the explicit, open access license to re-use all data and engage with the edition as a contributor. Digital by nature, the edition relies on feedback for its own enhancement, especially in the realm of cultural patrimonies. To many people (not only citizen scientists) this represents an important, and thus engageable, element that makes the edition applicable to their lives.

21 http://www.deutschestextarchiv.de/search/metadata?corpus=avh. 


\section{Alexander von Humboldt chronology - 1848}

Ed. by Ingo Schwarz

๑ Further information on this chronology

50 Hits

\section{Januar 1848}

H. signiert die Porträtzeichnung (Halbfigur, sitzend), zu der er Rudolf Lehmann in Paris gesessen hat.

\section{Januar 1848}

H. reist von Paris nach Berlin zurück. Übernachtungsorte: Brüssel, Deutz bei Köln (14.1.), Hannover.

16. Januar 1848

H. trifft in Berlin ein.

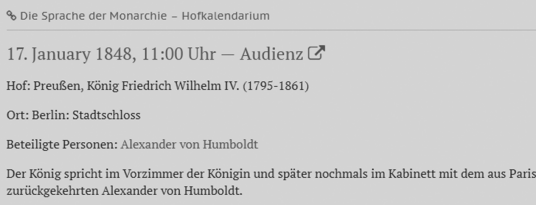

18. Januar 1848

H. nimmt an einem Kapitel des Schwarzen Adler-Ordens im Berliner Schloss teil.

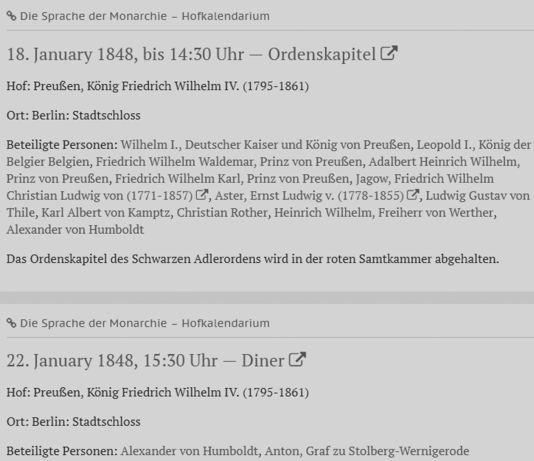

26. Januar 1848

H. wird auf der Gesamtsitzung der Kaiserlichen Akademie der Wissenschaften zu Wien zum Ausländischen Ehrenmitglied gewählt (Bestätigung am 1.2.1848).

\begin{tabular}{|l|}
\hline Browse \\
Year \\
\hline 1848 \\
\hline
\end{tabular}

Show further resources in Chronology

$\square$ Letters of this edition 0

Letters from and to Humboldt

Events with A.v. Humbolat in

Articles \& Papers by Humboldt

Humboldt's Works in the
Digital Bibliography 9

Submit

\section{$\odot$ Fulltext search}

Creating the data of the chronology is an ongoing process; the volume and accuracy project We are always grateful for any tips, additions, and corrections. Please write to edition-humboldt@bbaw.de.

Figure 4: Screenshot of the Humboldt Chronology from the year 1848 with entries from secondary digital resources. 


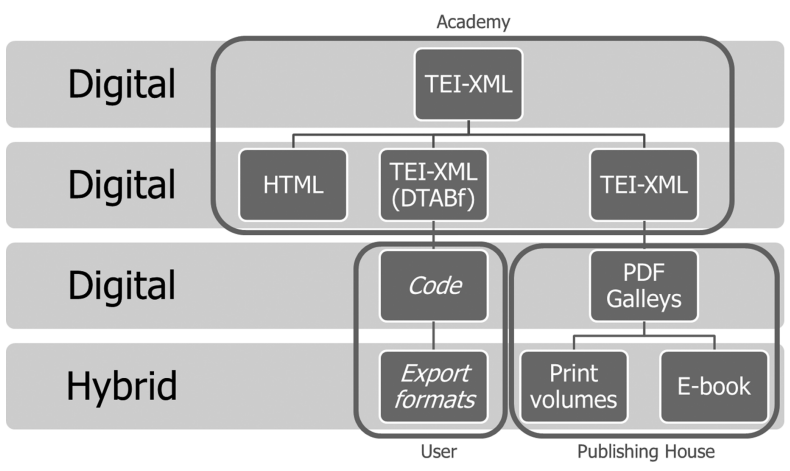

Figure 5: Diagram of the born-digital hybrid publication model.

This leads to a more general observation. Reading in the digital age, when it comes to scholarly editions, is about reading the text, re-using and adapting the code, and re-publishing that code, changed or unchanged, in almost any shape or form. This depends, of course, on the technological and conceptual competence of the reader (Figure 5). The prospects of this shift clearly expand the reader's profile as one that interacts with the scholarly, edited, digital text. The Danish scholar Krista Stinne Greve Rasmussen coined the term "co-worker" for this new reader role:

The co-worker seeks to go beyond the user and reader roles, and to contribute actively to the scholarly enterprise.[. . .] [I]deally speaking, the reader in this role is likely to take part in the editorial work at some level. This could consist of making annotations, reading proofs, adding encodings, or contributing in other ways to the site's total production of knowledge. The co-worker's contribution, in short, does not merely amount to additions or extensions, but forms a genuine part of the edition (Greve Rasmussen 2016: 127).

These different levels of interaction with the text and - possibly - its editors allow for something that goes beyond the attention for the text itself. A reader/user/co-worker that adapts, corrects or enhances a text does not just provide meaning and context for its inmediate usage, but also for the longterm goal of preserving the text's digital integrity. Use and re-use gives continuous proof of a resource worth to be curated actively, thus guaranteeing its continuous adapation to evolving standards (of data usage or display, for instance), because "digital resources that stay in use, also stay available” (Gärtner 2016: 21; translation T.K.). 


\section{The Reader as Publisher}

As stated above, the digital publication ideally makes all parts of scholarly work available beyond the textual level through expanding it into re-usable data sets and publication modules (Figure 6). The reader, who as a user can also become a co-worker, is able to re-engage with an original edition, thus simultaneously becomes a possible re-publisher of the text data.

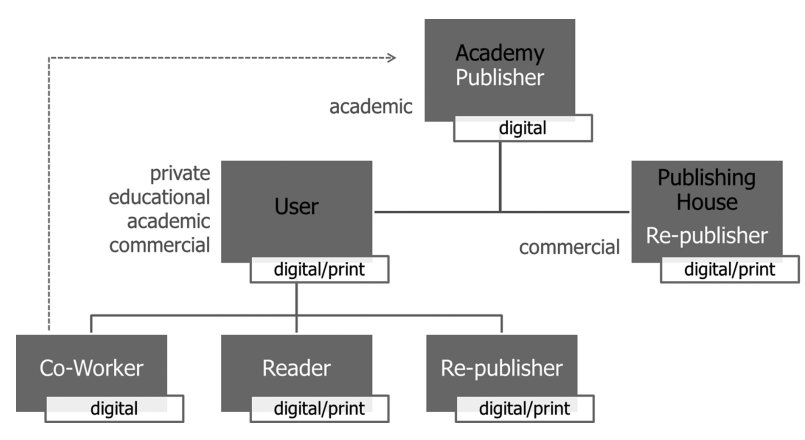

Figure 6: Diagram of the changing roles of publisher and user entities in the digital publication process.

In allowing for readers to decide upon their own role, a wide variety of settings become possible in which the process of contributing, reading, and re-publishing not only appear as distinct options of interaction with the text, but also become intertwined activities that create feedback loops in dialogue with the edition. The results of the readers' interactions with the text, either as text or as code-text (for instance through selection and recomposition, digital processing, quantitative and qualitative analysis, or recoding), can be published in almost any imaginable format, including possible commercial ones ${ }^{22}$. This development alone has, or should have, influence in the way we think about both digital and non-digital philology, the exercise of reading, and about the teaching of text cultures in academia today.

22 This results from the CC BY-SA 4.0 license valid for the edition humboldt digital, which permits commercial exploitation of the material whenever the edited source code is also made available under the same open license. For the details on the Creative Commons licensing model see https://creativecommons.org/licenses/by-sa/4.0/. 


\section{The Perspectives for Future (Digital) Philology}

Many of the methods and technological applications mentioned here, implemented both for the creation of a digital edition, as well as for its competent digital reading and methodological-collaborative-public exploration, require an informed user. Given the current state of affairs in literary studies and looking at the curricula of literature departments, at least in Germany, it is fair to say that we still have quite a way to go. Currently, we are producing scholarly editions for the future, that is, for a prototypical digital reader that so far only exists in highly specialized research communities. But this is changing. Three recent developments indicate that this transformation is in progress.

First and foremost, teaching is changing. This is reflected in the continuously rising amount of Digital Humanities chairs, with often literature- or textoriented profiles (Sahle 2019). New platforms that are evolving and shaping the way scholarly editions are formed and engaged with continue to emerge. There is, for instance, the important and particularly well-documented platform, forText, created and sponsored by a consortium of research institutions, projects, universities and the National Funding Agency DFG ${ }^{23}$. Even though it is not the first of its kind, forText succeeds in providing a high level of insight into the technological and methodological diversity of contemporary digital philology, while simultaneously offering very specific, hands-on tutorials, work packages, tools, and teaching modules, both at the university and high school level. The highly successful international platform, The Programming Historian, works in very similar ways. It currently provides 130, "novice-friendly, peer-reviewed tutorials that help humanists learn a wide range of digital tools, techniques, and workflows to facilitate research and teaching" 24 . The site, which publishes its content as stand-alone journals, operates without fees and is curated by an international community of digital humanities scholars in English, Spanish, and French.

Second, and no less important than the first observation, is the change in the reading habits of younger generations. This was very recently investigated in a large-scale study on the reading behavior of young readers using the Wattpad platform. An international team of researchers found that, contrary to common opinion (and also advocated for in this article), young readers: 1) read longer fictional texts on screen and 2) both the reading and the production of these texts is perceived as part of a social experience, which the authors call

23 https://fortext.net/.

24 https://programminghistorian.org/. 
“digital social reading” (Pianzola/Rebora/Lauer 2020). This experience of interface-induced social interaction is supposedly an effect of the platform's design, mostly due to the audience appeal that Wattpad has been able to create through focusing on fanfiction and genres related to teenagers, like coming-of-age stories. These findings do require a disclaimer, though. Fanfiction and teen literature are specific sets of texts, and thereby cannot fully reflect or represent tendencies or trends for the general public, nor can they accurately reflect literature as an art form. However, Wattpad's success obviously has a behavioral-changing effect on both authors and readers, providing, for the first time, a showcase of permeable role hierarchies between readers and authors (and old promise from digital literature) on a large scale and opening a possible pathway towards a shared reading culture that gathers around the common experience of reading in chapter installments (as this is a popular way of text production and author-reader-interaction on Wattpad) resembling to some degree the feuilleton-based literary production of the 19th century (Pianzola/Rebora/Lauer 2020: 35). This would indicate that the social approach may very well have an influence on reading habits and reading cultures, at least among young readers.

The impact of digital social reading might provide insights for future studies on world literature, as the authors of the Wattpad study are convinced that their, "results point out the rise of a global reading culture in youth reading besides national preferences for certain topics and genres, patterns of reading engagement, aesthetic values and social interaction" (Pianzola/Rebora/Lauer 2020: 1 , see also 33).

Finally - and this might be the most important conclusion so far - the humanities themselves have started to see that innovation in the realm of reading is not dependent on waiting for until publishers or an ambitious tech lab in California to come up with something new. Innovation and conceptual experiments can and should come directly from universities, academies, and humanities seminars themselves. This might, as all experiments may, lead to failure or new discoveries, or perhaps even breakthroughs. But it is important for reasons of self-affirmation, that the digital humanities, and digital philology in particular, take on the challenge of re-innovating the culture of reading as a new tech-integrated habit. Patrick Sahle, Chair of Digital Humanities in Wuppertal, and his research assistant, Sviatoslav Drach, are currently designing such a tool. The StreamReader ${ }_{S D}$ (Sahle/Drach: 2019, Drach: 2019) is an online interface designed to provide an experimental screen-reading experience that completely dismantles reading from the stability of paragraph- (and page-) oriented, stable text layout. It instead provokes the reader, who is able to choose from several texts or even upload their own material, to initiate a different reading experience and disrupt a more traditional conception of reading technique. Of course, the StreamReader interface is currently 
not available in the form of ready-made software and is far from being a product, but that is not the goal here. It presents, as Sahle points out in his abstract to the 2020 Digital Humanities Conference in Paderborn, an experimental setup for the exploration of digital reading.

The debate about reading digital texts (which, besides, does not exist; there is only the reading of various digitally driven text media) often revolves around the loss of concentration and deeper involvement with texts. On the other hand, one of the many aspects of the StreamReader is to allow the (forced?) slow and thus contemplative reading to maybe be given a new option. [. . . ] If text is reduced to a line of running text, then the new text medium presented creates completely new spaces for expression in the narrower sense. Reduction and expansion! Suddenly there are spaces in which new forms of text presentation can be experimentally created. By expanding the simple single line, contexts and hypertextual connections can be made more visible, texts can be illustrated or annotated in a positional manner and multiple or synoptic, interrelated streams of text can be realized (Sahle 2020: 257, translation DeepL).

The bottom line to all of this is that change is coming. And that is a very good message, because one thing is for sure: there are currently new Humboldts walking this planet. They will become the protagonists of our future debates on the cultural heritage we want to share, be it in the realm of science, literature, the arts, or all three combined. These future high achievers of our cultural memory will be distinct enough to be preserved for decades, given sufficient research funds, but this time it won't be in handwritten manuscripts and letters.

Do we know how to carry out these projects? In the midst of our digital revolution we are witnessing a new hiatus of sources. Digital data is being generated by people and machines on an enormous scale, and most of this data will soon be lost. Are we going to be able to store, archive, and recover the data produced by the Humboldts of today? Will we know and harvest the content of their Twitter feeds, their scattered email correspondences, their Slack working groups, the artwork canvases on their personal iPads, their contributions on Facebook, likes on Instagram, their favorite TikTok channels, viewing habits on YouTube, or the digital footprints of their Google Searches ${ }^{25}$ ? Do we want to harvest all or any of that? Who can be in charge of collecting this born digital life data? How do we process it in any meaningful way?

These are the tasks of a digital cultural heritage philology, which does not exist yet but needs to begin soon. The mission of this (not so far) distant future

25 Cross-sectoral research on these crucial matters has begun in the last five to seven years (Ries/Gábor 2019) and will forseeably hit the debates on scholarly digital editions in the near future. 
discipline will provide the foundations for the archeology of digital texts and media, which will require new skills, methods, technologies, and, above all, a developed culture of digital reading in order to advance. Philology has never been more exciting.

\section{Works Cited}

Amer, Karim/Barnett, Erin/Kos, Pedro (2019): “The Great Hack”. Netflix, <https://www.netflix. com/title/80117542> (last visit: 03/04/2020).

Barnett, Tully (2014): “Social Reading: The Kindle’s Social Highlighting Function and Emerging Reading Practices”. In: Australian Humanities Review 56, pp. 141-162, <http://australian humanitiesreview.org/2014/05/01/social-reading-the-kindles-social-highlightingfunction-and-emerging-reading-practices/> (last visit: 03/04/2020).

Börsenverein des Deutschen Buchhandels (2020): “Amazon setzt beim Einkauf andere Prioritäten. Der Verkauf gedruckter Bücher ist de facto für viele Verlage nicht mehr möglich". In: Börsenblatt Dossier Corona, <https://www.boersenblatt.net/2020-0320-artikel-_der_verkauf_gedruckter_buecher_ist_de_facto_fuer_viele_verlage_nicht_ mehr_moeglich_-amazon_setzt_beim_einkauf_andere_prioritaeten.1833523.html> (last visit: 03/04/2020).

Cannon, Susan F. (1978): Science in Culture: The Early Victorian Period. New York: Dawson. Cohen, Daniel J. (2012): "The Social Contract of Scholarly Publishing”. In: Gold, Matthew K. (eds.): Debates in the Digital Humanities. Minneapolis/London: University of Minnesota Press, <http://dhdebates.gc.cuny.edu/debates/text/27> (last visit: 04/03/2020).

Cummings, James (2008): "The Text Encoding Initiative and the Study of Literature". In: Siemens, Ray/Schreibman, Susan (eds.): A Companion to Digital Literary Studies, Oxford: Blackwell Publishers, pp. 451-476.

Dettelbach, Michael (1996): “Humboldtian Science”. In: Jardine, Nicholas/Secord, James A./ Spary, Emma C. (eds.): Cultures of Natural History. Cambridge: Cambridge University Press, pp. 287-304.

Drach, Sviatoslav (2019): Neue Leseformen in digitalen Umgebungen - StreamReader SD 0.1 als Webanwendung für Text als Zeichenstrom. Köln: Master's thesis.

Dumont, Stefan (2016): “correspSearch - Connecting Scholarly Editions of Letters". In: Journal of the Text Encoding Initiative 11, 〈http://journals.openedition.org/jtei/1742〉 (last visit: 10/02/2020).

Dumont, Stefan/Kraft, Tobias (2017): edition humboldt digital vernetzt [poster], <http://doi.org/10.5281/zenodo.1035134> (last visit: 10/02/2020).

Ette, Ottmar (2018): “Languages about Languages: Two Brothers and one Humboldtian Science". In: HiN - Alexander von Humboldt im Netz. Internationale Zeitschrift für Humboldt-Studien, 19, pp. 47-62, <http://doi.org/10.5281/10.18443/270> (last visit: 10/02/2020).

Evolution of Reading in the Age of Digitisation (E-READ) (eds.) (2019): Stavanger Declaration. Concerning the Future of Reading. European Cooperation in Science and Technology (COST), <https://ereadcost.eu/stavanger-declaration/>, (last visit: 03/04/2020). 
Fredericks, Joel/Caldwell, Glenda A./Foth, Marcus et al. (2019): "The City as Perpetual Beta: Fostering Systemic Urban Acupuncture”. In: de Lange, Michiel/de Waal, Martijn (eds.): The Hackable City. Singapore: Springer Singapore, pp. 67-92.

Gärtner, Kurt (2016): “Die Anfänge der Digital Humanities”. In: Akademie aktuell. Zeitschrift der Bayerischen Akademie der Wissenschaften 1, pp. 18-23.

Greve Rasmussen, Krista S. (2016): “7. Reading or Using a Digital Edition? Reader Roles in Scholarly Editions”. In: Driscoll, Matthew J./Pierazzo, Elena (eds.): Digital Scholarly Editing. Theories and Practices. Cambridge, UK: Open Book Publishers, pp. 119-133.

Hayles, N. Katherine (2010): “How We Read: Close, Hyper, Machine”. In: ADE 150, pp. 62-79, < http://doi.org/10.1632/ade.150.62> (last visit: 10/02/2020).

Kraft, Tobias/Dumont, Stefan (in press): “The Humboldt Code. On creating a hybrid digital scholarly edition of a $19^{\text {th }}$ century globetrotter". In: Wiener Digital Revue 1/1.

Lobo, Sascha (2018): “Facebook, die erste vernetzte Gefühlsmaschine”. In: Der Spiegel S.P.O.N. - Die Mensch-Maschine, 11/04/2018, <https://www.spiegel.de/netzwelt/web/sa scha-lobo-kolumne-was-facebook-wirklich-ist-a-1202360.html> (last visit: 03/04/2020).

Moretti, Franco (2013): Distant Reading. London: Verso.

Pianzola, Federico/Rebora, Simone/Lauer, Gerhard (2020): "Wattpad as a resource for literary studies. Quantitative and qualitative examples of the importance of digital social reading and readers' comments in the margins". In: PloS one 15, pp. 1-46.

Ries, Thorsten/Palkó, Gábor (2019): “Born-digital archives”. In: International Journal of Digital Humanities 1/1, pp. 1-11, <http://doi.org/10.1007/s42803-019-00011-x> (last visit: 10/02/2020).

Sahle, Patrick (2013a): Digitale Editionsformen - Teil 1: Das typografische Erbe. Zum Umgang mit der Überlieferung unter den Bedingungen des Medienwandels. Norderstedt: Books on Demand.

Sahle, Patrick (2013b): Digitale Editionsformen - Teil 2: Befunde, Theorie und Methodik. Zum Umgang mit der Überlieferung unter den Bedingungen des Medienwandels. Norderstedt: Books on Demand.

Sahle, Patrick (2019): “Professuren für Digital Humanities”. In: Blog des Verbandes Digital Humanities im deutschsprachigen Raum (DHd), 〈https://dhd-blog.org/?p=11018> (last visit: 10/02/2020).

Sahle, Patrick (2020): “Wie wir lesen könnten. Streamreader ${ }_{\text {PS }} 0.1$ ”. In: Schöch, Christof (eds.): DHd 2020 Spielräume: Digital Humanities zwischen Modellierung und Interpretation. Konferenzabstracts. Paderborn: Digital Humanities im deutschsprachigen Raum e.V., pp. 255-258, <https://doi.org/10.5281/zenodo.3666690> (last visit: 03/04/2020).

Sahle, Patrick/Drach, Sviatoslav (2019): StreamReader SD. Cologne Center for e-Humanities: Master's thesis.

Schöch, Christof (2016): “Ein digitales Textformat für die Literaturwissenschaften: Die Richtlinien der Text Encoding Initiative und ihr Einsatz bei Textkonstitution und Textanalyse”. In: Romanische Studien 2, pp. 325-364.

Schwarz. Ingo (eds.) (2017): “Alexander von Humboldt Chronologie. Basierend auf 'Alexander von Humboldt. Chronologische Übersicht über wichtige Daten seines Lebens. Bearbeitet von Kurt-R. Biermann, Ilse Jahn und Fritz G. Lange”. In: edition humboldt digital, <http://edition-humboldt.de/X0000001〉 (last visit: 25/08/2019).

Walsh, Brandon/Horowitz, Sarah (2016): Introduction to Text Analysis. A Coursebook, <http://walshbr.com/textanalysiscoursebook/> (last visit: 10/02/2020). 
